\title{
SO SÁNH HIỆU QUẢ TRỢ THỊ GẦN CHO NGƯỜI KHIẾM THI BẰNG KÍNH PHÓNG ĐẠI VÀ MÁY VIDEO PHÓNG ĐẠI CẦM TẢY
}

\section{TÓM TẮT}

Mục tiêu: So sánh hiệu quả trợ thị gần cho người khiếm thị bằng kính phóng đại và máy video phóng đại câm tay (Magnifier Video Handheld Device MViHD). Phương pháp nghiên cứu: nghiên cứu mô tả được thực hiện trên 80 người khiếm thị từ 7-71 tuổi. Kết quả: Công suất trung bình khi dùng kính phóng đại là $+24,6 \pm 11,4 \mathrm{D}$; Công suất trung bình khi dùng máy MVHD là $+18,8 \pm 8,3 \mathrm{D}$; Thị lực gần trung bình: trước trợ thị là 20/500 $\pm 20 / 630$; với kính phóng đai là 20/250 $\pm 20 / 500 ;$ với máy MVHD là 20/125 $\pm 20 / 320(p<0,001)$. Khoảng cách đọc: trước trợ thị là $4,42 \pm 2,81 \mathrm{~cm}$; với kính phóng đại là $7,74 \pm$ $4,17 \mathrm{~cm}$; với máy MVHD là $16,38 \pm 7,26 \mathrm{~cm}(p<0,001)$. Tốc độ đọc: trước trợ thị là $23,46 \pm 10,52$ từ/ phút; với kính phóng đại là 43,74 $\pm 22,57$ từ/ phút; với máy MVHD là $61,2 \pm 24,8$ từ/ phút $(p<0,001)$. Kết luận: So với kính phóng đại trợ thị gần cho người khiếm thị, máy MVHD cho thị lực nhìn gần, khoảng cách đọc và tốc độ đọc cải thiện hơon hẳn.

Tì̛ khóa: khiếm thị, kính phóng đại, máy video phóng đại cầm tay

\section{SUMMARY \\ COMPARISON ON THE EFFECT OF NEAR VISION AIDS FOR LOW VISION BY OPTICAL MAGNIFIERS AND MAGNIFIER VIDEO HANDHELD DEVICE}

Aims: To compare the effect of near vision aids for low vision by optical magnifiers and magnifier video handheld device. Methods: The descriptive study was conducted in 80 low vision people from 7 to 71 years old. Results: The average power of optical magnifiers was $+24.6 \pm 11.4 \mathrm{D}$. The average power of MVHD was $+18.8 \pm 8.3 \mathrm{D}$; Near visual acuity: before aids was 20/500 \pm 20/630; with optical magnifiers was $20 / 250 \pm 20 / 500$; with MVHD was 20/125 \pm $20 / 320(p<0.001)$. The reading distance: before aids was $4.42 \pm 2.81 \mathrm{~cm}$; with optical magnifiers was 7.74 $\pm 4.17 \mathrm{~cm}$; with MVHD was $16.38 \pm 7.26 \mathrm{~cm}$ $(p<0.001)$. The reading speed: before aids was 23.46 \pm 10.52 words/minute; with optical magnifiers was $43.74 \pm 22.57$ words/minute; with MVHD was $61.2 \pm$ 24.8 words/minute $(p<0.001)$. Conclusion: The near visual acuity, the reading distance, the reading speed of low vision by using the MVHD were much better than the use of the optical magnifiers.

Key words: low vision, optical magnifier, Magnifier Video Handheld Device.

${ }^{1}$ Bệnh viện Mắt trung ương

Chịu trách nhiệm chính: Nguyễn Thị Thu Hiên

Email: Thuhienvnio@gmail.com

Ngày nhận bài: 17.12.2020

Ngày phản biên khoa hoc: 22.01.2021

Ngày duyệt bài: 9.2.2021

\section{Nguyễn Thị Thu Hiền ${ }^{1}$}

\section{I. ĐĂT VẤN ĐỀ}

Trong cuộc sống hệ thống thị giác có ý nghĩa vô cùng quan trọng vì $80 \%$ thông tin mà con người tiếp nhận từ thế giới bên ngoài thông qua hệ thống thị giác. Chức năng thị giác phụ thuộc vào chất lượng hệ quang học mắt, sự toàn vẹn của hệ dẫn truyền thị giác, sự nhận diện của vỏ não và trình độ hiểu biết của con người.

Người khiếm thị là người bị tổn hại chức năng thị giác, điều này gây cho họ gặp rất nhiều khó khăn trong cuộc sống độc lập hàng ngày, đơn giản nhất như chăm sóc bản thân, cho đến giao tiếp, học tâp và làm việc. Chính vì vây người khiếm thị sẽ mất dần sự tự tin, sống khép mình và lệ thuộc vào người khác. Trợ thị cho người khiếm thị nhằm giúp họ cải thiện thị giác, giúp họ tận dụng phần thị giác còn lại tốt hơn để họ bớt khó khăn hơn trong cuộc sống độc lập và không còn là gánh nặng cho gia đình và xã hội. Người khiếm thị bị khiếm khuyết về mặt thị giác còn bộ não của họ hoàn toàn bình thường. Họ có nhu cầu học tập, khám phá cuộc sống, trong khi đó đọc là kỹ năng thu nhận thông tin hiệu quả để nẩng cao kiến thức và sự hiểu biết. Vì vậy trợ thị nhìn gần cho người khiếm thị giúp cải thiện chất lượng cuộc sống cho họ.

Có nhiêu phương pháp trợ thị nhìn gần cho người khiếm thị như các kính trợ thị quang học phóng đại, các phương pháp trợ thị phi quang học... Các kính trợ thị phóng đại đã được sử dụng từ những năm đầu của thế kỷ $X X$ và ngày càng được hoàn thiện hơn về hình thức, chất lượng giúp cho người khiếm thị cảm thấy thuận tiện hơon trong sử dụng. Tuy nhiên, trong một số trường hợp mặc dù đã được sử dụng kính phóng đại công suất rất cao nhưng bệnh nhân vẫn không thể đọc được chữ in cõ thông thường. Đồng thời các thiết bị phóng đại điện tử gần đây được chú ý hơn do nó có thể phóng đại vật tới hàng chục lần. Máy video phóng đại câm tay (Magnifier Video Handheld Device - MVHD) với thiết kế nhỏ gọn nhưng độ phóng đại lớn, có thể dùng để đọc sách báo, tap chí...xem những bức ảnh màu, với nhiều tính nằng ưu viêt giúp ích rất nhiều cho người khiếm thị, tuy nhiên giá thành của máy cao hơn nhiều so với các loại kính phóng đại.

ở Viêtt Nam chưa có nghiên cứu nào so sánh hiệu quả sử dụng các kính phóng đại với máy video phóng đại cầm tay để trợ thị nhìn gần cho 
người khiếm thị. Chính vì vậy, chúng tôi tiến hành nghiên cứu đề tài này nhằm mục đích: So sánh hiệu quả trợ thị gân bằng kính phóng đại và máy video phóng đại cầm tay trên người khiếm thị.

\section{II. ĐỐI TƯợNG VÀ PHƯƠNG PHÁP NGHIÊN CỨU}

2.1 Đối tượng nghiên cứu. Nghiên cứu được thực hiện trên bệnh nhân khiếm thị đến khám tại Đơn vị phục hôi chức năng khiếm thị của Bệnh viện Mắt Trung ương.

\section{Tiều chuâin lưa chon}

- Bênnh nhân khiếm thị từ 6 tuổi trở lên.

- Bệnh nhân có nhu câuu đọc, đồng ý tham gia nghiên cứu sau khi được tư vấn.

- Bênh nhân phải biết đọc, viết và có khả năng nhận thức tốt để có thể phối hợp thử các chức năng thị giác.

Tiêu chuẩn loại trư. Bệnh nhân đang mắc bệnh cấp tính hay tinh thân không ổn định.

\subsection{Phương pháp nghiên cứu}

Nghiên cứu mô tả cắt ngang.

Cỡ mẫu: $\mathrm{n}=80$ bênh nhân

Phương tiện nghiên cứu: Máy sinh hiển vi khám bệnh, máy soi đáy mắt, bảng thị lực nhìn gân bằng đoạn văn bản, kính phóng đại các loại: kính gọng, kính lúp, máy video phóng đại câm tay.

Nghiên cứu được tiến hành theo các bước như sau:

- Khám chẩn đoán nguyên nhân gây khiếm thị.

- Đánh giác chức năng thị giác bao gôm: thị lực gần, khoảng cách đọc và tốc độ đọc

- Thử trợ thị nhìn gân bằng kính phóng đại

- Thử trợ thị gân bằng máy video phóng đại câm tay

- Ghi hồ sơ nghiên cứu

Các số liệu được xử lý bằng thuật toán thống kê y học với sự trợ giúp của phần mềm SPSS 20.0

III. KẾT QUẢ NGHIÊN CỨU VÀ BÀN LUÂ̂N

\section{1. Đặc điểm nhóm bệnh nhân nghiên}

Bảng 1: So sánh thị lực gần trước trợ thị, với kính phóng đại và với máy MVHD

\begin{tabular}{|c|c|c|c|c|c|c|}
\hline \multirow{2}{*}{ Thị lực nhìn gân } & \multicolumn{2}{|c|}{ TL không kính } & \multicolumn{2}{c|}{ TL với kính phóng đại } & \multicolumn{2}{c|}{ TL với máy MVHD } \\
\cline { 2 - 7 } & $\mathbf{n}$ & $\mathbf{\%}$ & $\mathbf{N}$ & $\mathbf{\%}$ & $\mathbf{n}$ & $\mathbf{\%}$ \\
\hline $20 / 200-20 / 60$ & 6 & 7,5 & 24 & 30,0 & 80 & 100,0 \\
\hline $20 / 400-20 / 200$ & 22 & 27,5 & 34 & 42,5 & 0 & 0 \\
\hline $20 / 1200-20 / 400$ & 40 & 50 & 22 & 27,5 & 0 & 0 \\
\hline$\leq 20 / 1200$ & 12 & 15 & 0 & 0 & 0 & 0 \\
\hline Tống & $\mathbf{8 0}$ & $\mathbf{1 0 0 , 0}$ & $\mathbf{8 0}$ & $\mathbf{1 0 0 , 0}$ & $\mathbf{8 0}$ & $\mathbf{1 0 0 , 0}$ \\
\hline
\end{tabular}

Trước trợ thị, thị lực nhìn gân trung bình là lên đến 20/125 $\pm 20 / 320$, sự khác biệt này có ý 20/500 \pm 20/630; sau khi thử dùng kính phóng đại, thị lực đã cải thiện trên 20/250 \pm 20/500, sự khác biệt này có ý nghĩa thống kê với $p<0,001$; nhưng khi dùng MVHD thị lực gân đã cải thiện cứu. Tuổi trung bình của 80 bệnh nhân nghiên cứu của chúng tôi là $24,94 \pm 13,5$; trong đó thấp nhất là 7 tuối và cao nhất là 71 tuổi, tập trung chủ yếu ở nhóm tuổi 19-50, chỉ có 3 bệnh nhân trên 50 tuổi. Tuổi trung bình nhóm nghiên cứu của chúng tôi thấp hơn rất nhiều so với các tác giả nước ngoài như Chia - Yun Li (tuổi trung bình là 38,8 $\pm 25,2$ ), hay Margrain (tuổi trung bình là 76); rõ ràng tỳ lệ người khiếm thị ở nước ngoài chủ yếu là người cao tuổi. Điều này có nghĩa là ở lứa tuổi trẻ em và độ tuổi lao động tỷ lệ người khiếm thị do các bệnh mắt mắc phải là rất thấp và việc điều trị bệnh kịp thời đã làm giảm thiểu tỷ lệ di chứng của bệnh.

Nguyên nhân gầy khiếm thị: trong số 80 bệnh nhân thì có $81,2 \%$ trường hợp là do các nguyên nhân gây tổn hại thị lực - thị trường trung tâm và chỉ có $18,8 \%$ trường hợp là do các nguyên nhân gây tổn hại thị lực - thị trường chu biên. Trong đó bệnh lý thể thủy tinh là nguyên nhân hàng đầu gây khiếm thị chiếm tỷ lệ 32,5\%; nhóm nguyên nhân thường gặp thứ hai là các bệnh lý võng mạc hoàng điểm $(26,2 \%)$; nhóm nguyên nhân thường gặp thứ ba là các bệnh lý của thị thần kinh $(11,2 \%)$.Nghiên cứu của chúng tôi cũng phù hợp với kết quả của tác giả Owsley.

Thị lực gần của bệnh nhân trong nhóm nghiên cứu rất kém, chỉ có 6 bệnh nhân $(7,5 \%)$ thị lực nhìn gần trong khoảng 20/200 đến 20/60, và có tới 12 bệnh nhân (15\%) thị lực nhìn gân ở mức dưới 20/1200.

3.2. So sánh hiệu quả sử dụng kính phóng đại và máy video phóng đại cầm tay. Công suất trung bình của kính phóng đại trợ thị gần cho 80 bệnh nhân là $+24,6 \pm 11,4 \mathrm{D}$ trong đó công suất thấp nhất là $+8 \mathrm{D}$ và cao nhất là +50D. Công suất trung bình khi dùng máy MVHD trợ thị gần cho 80 bệnh nhân là $+18,8 \pm 8,3 \mathrm{D}$; trong đó công suất thấp nhất là $+10 \mathrm{D}$ và cao nhất là +40D. nghĩa thống kê với $p<0,001$. So với thị lực trước trợ thị, thị lực sau trợ thị tăng đáng kể, đăc biệt sau dùng máy MVHD, sự khác biệt này có ý nghĩa thống kê với $p<0,001$. Công suất 
trung bình của MVHD và TL gần với máy MVHD có mối tương quan tuyến tính nghịch $(r=-0,42)$ nhưng $p>0,05$ có nghĩa là công suất trung bình của MVHD không ảnh hưởng đến TL gần sau MVHD.

So sánh với phương pháp sử dụng kính phóng đại, phương pháp trợ thị bằng máy MVHD thị lực nhìn gần được cải thiện hơn hẳn $(\mathrm{p}<$ $0,001)$, điều này đồng thới thế hiện: với kính phóng đại có $30 \%$ bệnh nhân có thể đọc được nội dung bản in báo bình thường nhưng với máy MVHD thì toàn bộ $100 \%$ bệnh nhân có thể đọc được. Đạt được hiệu quả như vậy có thể do hầu hết bệnh nhân khiếm thị của chúng tôi nguyên nhân gây khiếm thị là các bệnh lý gây giảm thị lực trung tâm. Kết quả nghiên cứu này cũng phù hợp với các tác giả nước ngoài như Chia - Yun Li thấy rằng tỉ lệ thành công là $92 \%$ khi sử dụng MVHD, tác giả Nguyễn Xuân Nhung nghiên cứu trên 530 bệnh nhân khiếm thi do thoái hóa hoàng điểm tuổi già ở Đức thấy trước trợ thị chỉ có $16 \%$ bệnh nhân có thể đọc được chữ in nội dung báo nhưng sau trợ thị bằng máy MVHD số bệnh nhân đọc được nội dung báo là $94 \%$.

Bảng 2: So sánh khoảng cách đọc trước trợ thị, với kính phóng đại và với máy MVHD

\begin{tabular}{|c|c|c|}
\hline $\begin{array}{c}\text { Khoảng cách đọc TB } \\
\text { trước trợ thị (cm) }\end{array}$ & $\begin{array}{c}\text { Khoảng cách đọc TB với } \\
\text { kính phóng đại } \mathbf{( c m})\end{array}$ & $\begin{array}{c}\text { Khoảng cách đọc TB với máy } \\
\text { MVHD (cm) }\end{array}$ \\
\hline $4,42 \pm 2,81$ & $7,74 \pm 4,17$ & $16,38 \pm 7,26$ \\
\hline \multicolumn{3}{|c|}{$p<0,001$} \\
\hline
\end{tabular}

Khoảng cách đọc của bệnh nhân sau khi sử dụng kính phóng đại hay máy MVHD đều được cải thiện, tuy nhiên với máy MVHD khoảng cách đọc cải thiện hơn hẳn so với kính phóng đại, sự khác biệt có ý nghĩa thống kê với $p<0,001$. Khoảng cách đọc trung bình với MVHD trợ thị gần cho 80 bệnh nhân là 16,38 $\pm 7,26 \mathrm{~cm}$, trong đó khoảng cách đọc gần nhất là $5 \mathrm{~cm}$, khoảng cách đọc xa nhất là $30 \mathrm{~cm}$.

Công suất trung bình của các kính phóng đại và khoảng cách đọc sau sử dụng kính phóng đại có mối tương quan tuyến tính nghịch $(r=-0,26$; $\mathrm{p}<0,05)$ có nghĩa là công suất kính càng cao thì khoảng cách đọc càng gần. Công suất trung bình với máy MVHD và khoảng cách đọc sau sử dụng máy MVHD có mối tương quan tuyến tính thuận $(r=0,79 ; p>0,05)$ có nghĩa là chưa thây mối

liên quan giữa công suất máy MVHD và khoảng cách đọc sau sử dụng MVHD.

Với kính phóng đại công suất kính càng cao thì khoảng cách đọc càng gần sẽ làm người đọc phải tư thế cúi sát vào vật gây cản trở ánh sáng chiếu vào vật, nhưng với máy MVHD dù công suất phóng đai cao nhưng thiết bi vẫn cho hình ảnh rõ nét, khoảng cách làm việc xa hơn so với kính phóng đại quang học, tạo thuận lợi hơn hẳn cho bệnh nhần khi phải đọc lâu. Ngoài ra khi nhìn qua kính phóng đại công suất càng cao nếu khoảng cách từ mắt đển kính càng xa thì trường nhìn càng bị thu hẹp và hiện tượng méo hình ở vùng chu biên của kính càng rõ rệt, nhưng hiện tượng méo hình không xảy ra khi dùng máy $M V \dot{H D}$ vì màn hình của máy là mặt kính phẳng.

\section{Bảng 3: So sánh tốc độ đọc trước trợ thị, với kính phóng đại và với máy MVHD}

\begin{tabular}{|l|l|l|l|l}
\hline Tốc độ đọc TB trước trợ & Tốc độ đọc TB với kính & Tốc độ đọc TB với máy MVHD
\end{tabular}
thị (từ/ phút) $23,46 \pm 10,52$ phóng đại (từ/ phút) (từ'/ phút) $61,2 \pm 24,8$

Tốc độ đọc trung bình của 80 bệnh nhân trước trợ thị là $23,46 \pm 10,52$; sau khi thử dùng kính phóng đại tốc độ đọc đạt 43,74 $\pm 22,57$ và nhưng với máy MVHD tốc độ đọc tăng lên 61,2 $\pm 24,8$ từ/ phút. Sự khác biệt này có ý nghĩa thống kê với $p<0,001$. Việc dùng MVHD cho tốc độ đọc hơn hẳn khi sử dụng kính trợ thị quang học phóng đại bởi màn hình của MVHD phẳng và không bị ảnh hưởng bởi hiện tượng quang sai khi độ phóng đại càng cao.

Cồng suất trung bình của kính phóng đại và tốc độ đọc sau sử dụng kính phóng đại có mối tương quan tuyến tính nghịch $(r=-0,32 ; p=$ $0,01)$ nghĩa là công suất kính càng cao thì tốc độ 0,001

đọc càng chậm. Công suất trung bình của máy MVHD và tốc độ đọc với máy MVHD có mối tương quan tuyển tính nghịch $(r=-0,56 ; p>$ $0,05)$ có nghĩa chưa đủ bằng chứng đế kết luận giữa công suất trung bình của MVHD và tốc độ đọc với máy MVHD có liên quan với nhau.

Tốc độ đọc sau sử dụng máy MVHD và khoảng cách đọc với máy MVHD có mối tương quan tuyến tính thuận $(r=0,38 ; p=0,001)$, nghĩa là khoảng cách đọc sau sử dụng máy MVHD tăng thì tốc độ đọc với máy MVHD cũng tăng.

Tốc độ đọc sau sử dụng kính phóng đại và khoảng cách đọc với kính phóng đại có mối tương quan tuyến tính thuận $(r=0,23 ; p=$ 
0,05) nghĩa là khoảng cách đọc sau sử dụng kính phóng đại tăng thì tốc độ đọc với kính cũng tăng.

Chọn màu sắc màn hình sẽ giúp cho bệnh nhân đọc tốt nhất, trong nhóm bệnh nhân nghiên cứu, có tới 44 bệnh nhân chọn nền trắng chữ đen $(55,0 \%)$, sau đó có 34 bệnh nhân $(42,5 \%)$ chọn nền đen chữ trắng, chỉ có 2 bệnh nhân chọn nền đen chữ vàng $(2,5 \%)$, không có bệnh nhân ( $0 \%)$ nào chọn nền xanh chữ trắng hay nền vàng chữ xanh, tuy nhiên sự lựa chọn màu sắc màn hình không liên quan đến mức độ thị lực tương phản của các bệnh nhân, kết quả của chúng tôi cũng phù hợp với tác giả Zabel.

Tuy nhiên, tác giả Ehrlich và Sanberg chứng minh rằng bệnh nhân võng mạc sắc tố đọc tốt hơn với màn hình nền đen chữ trắng còn tác giả Jacobs lại cho rằng sự lựa chọn màu sắc màn hình là sở thích chủ quan của từng cá nhân.

\section{KẾT LUÂN}

So với kính phóng đại trợ thị gân cho người khiếm thị, máy MVHD cho thị lực nhìn gần, khoảng cách đọc và tốc độ đọc cải thiện hơn hẳn.

\section{TÀI LIẸU THAM KHẢO}

1. Carmen, W. (2015) Video magnifiers, Teaching students with visual impairments, teachingvisuallyimpaired.com.

2. Carvalho, K. M. (2004). Causes of low vision and use of optical aids in the elderly, Rev. Hosp. Clin. Fac. Med. S. Paulo, 59(4), 157-60.

3. Chia-Yun Li, M. D. (2002). Low vision and Methods of Rehabilitation: A Comparison between the Past and Present. Chang Gung Med J, 25, 153-61.

4. Harvey, W. J. (2004). Electronic low vision aids, a new image for the visually impaired, Optical, 227.

5. Margrain, T. H. (2000). Helping blind and partially sighted people to read: the effectiveness of low vision aids, BJO, 84(8), 919-21.

6. Nguyễn Xuân Nhung (2009). Improvement of reading speed after providing of low vision aids in patients with age - related macular degeneration, Acta Ophthalmol, 87, 849-53.

7. Owsley, C. , Lee, P. P. (2009). Characteristics of low vision rehabilitation services in United States, Arch Ophthalmol, 127 (5), 681- 89.

8. Sandberg, M. A. , Gaudio A. R. (2006). Reading speed of patients with advanced retinitis pigmentosa or choroideremia, Retina, 26(1), 80-8.

\title{
ĐÁNH GIÁ TÁC DUNG KHÔNG MONG MUỐN CỦA GÂY TÊ TỦY SỐNG BẰNG BUPIVACAIN KẾT HỢP VỚI CÁC LIỀU MORPHIN KHÁC NHAU TRONG PHẪU THUÂTT CHẤN THƯƠNG CHI DƯớI
}

\author{
Dương Đức Phúc*, Công Quyết Thắng**, Lư Quang Thùy***
}

\section{TÓM TĂT}

Mục tiêu: So sánh tác dụng không mong muốn của GTTS bằng $8 \mathrm{mg}$ bupivacain $0.5 \%$ kết hợp với $100 \mathrm{mcg}, 200 \mathrm{mcg}, 300 \mathrm{mcg}$ morphin trong phẫu thuật chấn thương chi dưới tại bệnh viện Quân Y 105 từ tháng 11/2018 đến tháng 04/2019. Phương pháp nghiên cứu: Thử nghiệm lâm sàng, tiến cứu, có nhớm so sánh. Bệnh nhần được chia vào 03 nhóm ngẫu nhiên: Nhóm I gồm 40 bệnh nhân được GTTS bằng bupivacain liêu $8 \mathrm{mg}$ kểt hợp với morphin $0,10 \mathrm{mg}$. Nhóm II gồm 40 bệnh nhân được GTTS bằng bupivacain liều $8 \mathrm{mg}$ kết hợp với morphin 0,20mg. Nhóm III gồm 40 bệnh nhân được GTTS bằng bupivacain liều $8 \mathrm{mg}$ kết hợp với morphin $0,3 \mathrm{mg}$. Kết quả nghiên cứu: Sư thay đổi về mạch và huyết áp cũng như các thay đối về hô hấp: $\mathrm{SpO} 2$, tân số thở tại

*Bệnh viện Quân Y 105,

**aai họ Y Hà Nội

***Bệnh viện Việt Đức

Chịu trách nhiệm chính: Dương Đức Phúc

Email: duongducphuc@gmail.com

Ngày nhận bài: 14.12 .2020

Ngày phản biện khoa học: 26.01.2021

Ngày duyệt bài: 10.2.2021 các thời điểm nghiên cứu không nhiều, trong giới hạn bình thường và không có sư khác biêt giữa ba nhóm với $p>0,05$. Các tác dụng khác như bí tiểu, nôn, rét run, đau đâu không có sự khác biệt giữa 3 nhóm. Kết luận: Liều dùng morphin giảm đau: nên dùng liều $0,3 \mathrm{mg}$ vì tác dung không mong muốn không có sư khác biệt so với liều $0,2 \mathrm{mg}$ hay $0,1 \mathrm{mg}$ mà tác dụng vồ cảm và giảm đau tốt hơn.

Tư khóa: gây tê tủy sông, bupivacaine, morphin

\section{SUMMARY}

EVALUATE THE SIDE EFFECTS OF SPINAL ANESTHESIA BY BUPIVACAIN COMBINED WITH DIFFERENT MORPHIN DOSES IN LOWER EXTREMITY SURGERY

Objective: To compare the side effects of spinal anesthesia by $8 \mathrm{mg}$ bupivacaine $0.5 \%$ combined with $100 \mathrm{mcg}$, 200mcg, $300 \mathrm{mcg}$ morphine in lower extremity surgery at 105 Military Hospital from November 2018 to April 2019. Method: prospective randomized controlled trial interventional study. The patients were divided into three random groups: Group I included 40 patients who received $8 \mathrm{mg}$ bupivacaine combined with $0,1 \mathrm{mg}$ morphine. Group II consisted of 40 patients who received $8 \mathrm{mg}$ bupivacaine combined with 0,2 mg morphine. Group 